\title{
Design and Synthesis of a New Androgen Derivative using Some Strategies
}

\author{
FIGUEROA-VALVERDE LAURO ${ }^{1 *}$, DÍAZ-CEDILLO FRANCISCO², GARCÍA-CERVERA \\ ELODIA', 'POOL-GÓMEZ EDUARDO, 1'LÓPEZ-RAMOS MARIA, ${ }^{3}$ ROSAS-NEXTICAPA \\ MARCELA, HAU-HEREDIA LENIN ${ }^{1}$, B. SARABIA ALCOCER ${ }^{4}$ and B. ZEPEDA-ACOSTA ${ }^{1}$
}

${ }^{1}$ Laboratory of Pharmaco-Chemistry, Faculty of Chemical Biological Sciences, University Autonomous of Campeche, Av. Agustín Melgar s/n, Col Buenavista C.P.24039 Campeche Cam., México.

Escuela Nacional de Ciencias Biológicas del Instituto Politécnico Nacional.

Prol. Carpio y Plan de Ayala s/n Col. Santo Tomas, México, D.F. C.P. 11340.

${ }^{3}$ Facultad de Nutrición, Universidad Veracruzana, Médicos y Odontologos s/n C.P. 91010 ,

Unidad del Bosque Xalapa Veracruz, México.

${ }^{4}$ Faculty of Medicine, University Autonomous of Campeche, Av. Patricio Trueba

de Regil s/n, Col Lindavista C.P.24090 Campeche Cam., México.

*Corresponding author E-mail: lauro_1999@yahoo.com

http://dx.doi.org/10.13005/ojc/290403

(Received: November 04, 2013; Accepted: November 28, 2013)

\begin{abstract}
Anew androgen derivative was synthesized using some strategies; in the first stage the compound of $\mathrm{N}$-(1,10-phenanthrolin-5-ylmethyl)ethane-1,2-diamine (3)was obtained by the reaction of 1,10-phenanthroline with ethylenediamine in presence of formaldehyde. The second stage was achieved by the reaction of 3 with testosterone using boric acid as catalyst to form the compound 10,13-dimethyl-3-\{2-[([1,10]phenanthrolin-5-ylmethyl)-amino]-ethylimino\}-2,3,6,7,8,9,10,11,12,1 $3,14,15,16,17$-tetradecahydro-1H-cyclopenta[a]phenanthren-17-ol (5). Finally, the compound 7 (Chloro-acetic acid 3-((3-chloro-2-oxo-cyclobutyl)-\{2-[(3-chloro-2-oxo-cyclobutyl)-[1,10]phenanthrolin5-ylmethyl-amino]ethyl\}-amino)-10,13-dimethyl-2,3,6,7,8,9,10,11,12,13,14,15,16,17-tetradecahydro$1 \mathrm{H}$-cyclopenta[a]phenanthren-17-yl ester was synthesized by thereaction of $\mathbf{5}$ with chloroacetyl chloride in presence of triethylamine. The structure of the compounds obtained was confirmed by elemental analysis, spectroscopy and spectrometry data. The proposed method offers some advantages such as good yields, simple procedure, low cost, and ease of workup.
\end{abstract}

Key words: 1,10-phenanthrolin, testosterone, boric acid.

\section{INTRODUCTION}

There are several reports on development of some androgen derivatives; for example, the synthesis of $17 \alpha$-(tributylstannylethynyl)-4- androsten-17-ol-3-one by the reaction of 17ethynyl-4-androsten-17-ol-3-one with $\mathrm{Bu}_{3} \mathrm{SnOMe}$ to reflux ${ }^{1}$. Other data indicate the preparation of 3-oxoandrost-4-en-17 $\beta$-yl-2-methyl-1H-imidazole1 -carboxylate by the reaction of 17-hydroxyandrost- 
4-en-3-one-1,1-carbonylbis(2-methylimidazole) in anhydrous acetonitrile ${ }^{2}$. In addition, other study showed the synthesis of (17S)-spiro-3,3(dimethoxy)-5 $\alpha$-androstan-17 $\beta, 2^{\prime}$-oxirane by the reaction of 3,3-(dimethoxy)-5 $\alpha$-androstan-17-one with trimethylsulfonium iodide in $\mathrm{DMF}^{3}$. There is other reportwhich shown the synthesis of the dehydroisoandrosterone derivative by the reaction between a brucine derivative anddehydroiso androsterone 3 -sulfate using boric acid as catalyst ${ }^{4}$. Other data indicate the preparation of 17-(2-[[(2hydroxy-naphtalen-1-yl)phenyl-methyl]-amino]ethyl amino)-10,13-dimethyl-2,2,6,7,8,9,10,11,12,13, 14,15,16,17-tetradecahydro- $1 \mathrm{H}$-cyclopenta [a] phenanthren-3-ol by the reaction between 1-[(2amino-ethylamino)- phenyl-methyl]-naphthalen-2-ol and androsterone using boric acid as catalyst ${ }^{5}$. Additionally, other androgen (Succinic acid mono\{6-[(2-amino-ethylamino)-methyl]-1-ethinyl-10a,12adimethyl-2,3,3a,3b,4,5,10,10a,10b, 11,12,12adodecahydro-1H-7-oxa-8-aza-dicyclopenta[a,h]-phenanthren-1-yl\}ester) was prepared by reaction of hemisuccinate of danazol with ethylenediamine hydrochloride in presence of formaldehyde 6 . Also Other report ${ }^{7-9}$ indicate the preparation of $17^{2}-(\mathrm{N}$-Acetyl-42 -imidazolyl)-3 $\beta$ acetoxyandrost-5-ene by the reaction of $17 \beta-(42$ -Imidazolyl)androst-5-en-32-ol in pyridine/ $\mathrm{Ac}_{2} \mathrm{O}$.All these experimental results show several procedures which are available for synthesis of diverse androgen derivatives; nevertheless, expensive reagents and special conditions are required. Therefore, in this study anandrogen derivative was synthesized using some strategies.

\section{EXPERIMENTAL}

The compounds evaluated in this study were purchased from Sigma-Aldrich Co. Ltd. The melting points for the different compounds were determined on an Electrothermal (900 model). Infrared spectra (IR) were recorded using $\mathrm{KBr}$ pellets on a Perkin Elmer Lambda 40 spectrometer. ${ }^{1} \mathrm{H}$ and ${ }^{13} \mathrm{C}$ NMR spectra were recorded on a Varian VXR300/5 FT NMR spectrometer at 300 and $75.4 \mathrm{MHz}$ in $\mathrm{CDCl}_{3}$ using TMS as internal standard. EIMS spectra were obtained with a Finnigan Trace GCPolaris Q. spectrometer. Elemental analysis data were acquired from a Perkin Elmer Ser. II CHNS/0 2400 elemental analyzer.
$N$-(1,10-phenanthrolin-5-ylmethyl)ethane-1,2diamine (3)

A solution of 1,10-phenanthroline (100 mg, $0.55 \mathrm{mmol})$, ethylenediamine $(100 \mu \mathrm{l}, 1.50 \mathrm{mmol})$ and $10 \mathrm{ml}$ of formaldehyde was stirred for $72 \mathrm{~h}$ to room temperature. The reaction mixture was evaporated to a smaller volume. After the mixture was diluted with water and extracted with chloroform. The organic phase was evaporated to dryness under reduced pressure, the residue was purified by crystallization from methanol:water (3:1) yielding $85 \%$ of product, m.p. $98^{\circ} \mathrm{C}$; IR $\left(\mathrm{V}_{\max }, \mathrm{cm}^{-1}\right)$ : 3382, 3310,1540; ${ }^{1} \mathrm{H}$ NMR $\left(300 \mathrm{MHz}, \mathrm{CDCl}_{3}\right) \delta_{\mathrm{H}}: 2.40$ (broad, 3H), 2.69(t, 2H, $\mathrm{J}=6.0), 2.83 \mathrm{t}, 2 \mathrm{H}, \mathrm{J}=6.0), 3.53(\mathrm{~m}, 2 \mathrm{H}), 7.27-8.12$ $(\mathrm{m}, 4 \mathrm{H}), 8.18-8.78(\mathrm{~m}, 2 \mathrm{H}), 8.87(\mathrm{~d}, 1 \mathrm{H}, \mathrm{J}=4.0 \mathrm{~Hz})$ ppm. ${ }^{13} \mathrm{C}$ NMR $\left(75.4 \mathrm{MHz}, \mathrm{CDCl}_{3}\right) \mathrm{d}_{\mathrm{C}}: 41.50,53.12$, 53.48, 120.90, 123.17, 127.50, 129.15, 130.42, 133.91, 135.02, 141.08, 144.10, 145.12, 148.20, 152.03 ppm. El-MS m/z:252.12 (M+10). Anal.Calcd. for $\mathrm{C}_{15} \mathrm{H}_{16} \mathrm{~N}_{4}$ : C, 71.40; $\mathrm{H}, 6.39 ; \mathrm{N}, 22.21$. Found: $\mathrm{C}$, 71.38; H, 6.36.

10,13-dimethyl-3-\{2-[([1,10]phenanthrolin-5ylmethyl)-amino]-ethylimino\}-2,3,6,7,8,9,10, 11,12, 13,14,15,16,17-tetradecahydro-1H-cyclopenta [a] phenanthren-17-ol(5)

A solution of $3(100 \mathrm{mg}, 0.40 \mathrm{mmol})$, testosterone (118 $\mathrm{mg}, 0.40 \mathrm{mmol})$ and boric acid (90 $\mathrm{mg}, 1.45 \mathrm{mmol}$ ) in $10 \mathrm{ml}$ of methanol was stirred for $72 \mathrm{~h}$ to room temperature. The reaction mixture was evaporated to a smaller volume. After the mixture was diluted with water and extracted with chloroform. The organic phase was evaporated to dryness under reduced pressure, the residue was purified by crystallization from methanol:water (4:1) yielding 62 $\%$ of product, m.p. $80-82^{\circ} \mathrm{C}$; IR $\left(\mathrm{V}_{\max }, \mathrm{cm}^{-1}\right): 3410$, 3324, 3312; ${ }^{1} \mathrm{H}$ NMR $\left(300 \mathrm{MHz}, \mathrm{CDCl}_{3}\right) \delta_{\mathrm{H}}: 0.80$ (s, $3 \mathrm{H}), 0.92-1.00(\mathrm{~m}, 2 \mathrm{H}), 1.02(\mathrm{~s}, 3 \mathrm{H}), 1.06-1.40 \mathrm{~m}$, $6 \mathrm{H}), 1.56-1.62(\mathrm{~m}, 4 \mathrm{H}), 1.86(\mathrm{~m}, 2 \mathrm{H}), 2.04-2.38(\mathrm{~m}$, $5 \mathrm{H}), 3.04(\mathrm{t}, 2 \mathrm{H}, \mathrm{J}=6.44 \mathrm{~Hz}), 3.50(\mathrm{t}, 2 \mathrm{H}, J=6.44$ $\mathrm{Hz}), 3.68(\mathrm{~m}, 1 \mathrm{H}), 4.10(\mathrm{t}, 2 \mathrm{H}, J=6.44 \mathrm{~Hz}), 4.70$ (broad, 2H), 5.97 (d, 1H, J = 1.84), 7.20-7.80 (m, $7 \mathrm{H}) \mathrm{ppm} .{ }^{13} \mathrm{C}$ NMR $\left(75.4 \mathrm{MHz}, \mathrm{CDCl}_{3}\right) \delta_{\mathrm{C}}: 11.133$, $17.75,20.75,23.38,30.11,30.27,30.4,32.98$, $33.21,35.58,36.64,37.86,50.61,50.97,51.01$, $51.73,53.16,80.72,115.5,120.95,124.35,127.54$, $129.51,133.18,134.09,136.84,141.08,145.18$, 146.49, 148.29, 155.11, 157.83, 165.96 ppm.El-MS $\mathrm{m} / \mathrm{z}: 522.30\left(\mathrm{M}^{+} 12\right)$. Anal. Calcd. for $\mathrm{C}_{34} \mathrm{H}_{42} \mathrm{~N}_{4} \mathrm{O}: \mathrm{C}$, 78.12; H, 8.10; N, 10.72; O, 3.06. Found: C, 78.10; H, 8.08. 
Chloro-aceticacid 3-((3-chloro-2-oxocyclobutyl)-\{2-[(3-chloro-2-oxo-cyclobutyl)$[1,10]$ phenanthrolin-5-ylmethyl-amino]ethyl\}amino)-10,13-dimethyl-2,3,6,7,8,9,10,11, 12, $13,14,15,16,17$-tetradecahydro-1 $\mathrm{H}$-cyclopenta [a]phenanthren-17-yl ester (7)

A solution of $5(200 \mathrm{mg}, 0.38 \mathrm{mmol})$, triethylamine $(100 \mu \mathrm{l}, 1.50 \mathrm{mmol})$ and chloroacetyl chloride $(128 \mu \mathrm{l}, 1.60 \mathrm{mmol})$ in $10 \mathrm{ml}$ of methanol was stirred for $72 \mathrm{~h}$ to room temperature. The reaction mixture was evaporated to a smaller volume. After the mixture was diluted with water and extracted with chloroform. The organic phase was evaporated to dryness under reduced pressure, the residue was purified by crystallization from methanol:water (4:1) yielding $70 \%$ of product, m.p. $122{ }^{\circ} \mathrm{C}$; IR $\left(\mathrm{V}_{\max }, \mathrm{cm}^{-1}\right)$ : 1738, 1705, 1208; ${ }^{1} \mathrm{H}$ NMR $\left(300 \mathrm{MHz}, \mathrm{CDCl}_{3}\right) \delta_{\mathrm{H}}$ : $0.76(\mathrm{~m}, 1 \mathrm{H}), 0.80(\mathrm{~s}, 3 \mathrm{H}), 0.86(\mathrm{~m}, 1 \mathrm{H}), 1.00(\mathrm{~s}, 3 \mathrm{H})$, 1.06-1.18 (m, 2H), 1.50-1.66 (m, 7H), $1.69(\mathrm{~m}, 1 \mathrm{H})$, $1.72(\mathrm{~m}, 1 \mathrm{H}), 1.80(\mathrm{~m}, 1 \mathrm{H}), 1.88-1.90(\mathrm{~m}, 2 \mathrm{H}), 1.96$ $(\mathrm{m}, 1 \mathrm{H}), 2.06(\mathrm{~m}, 1 \mathrm{H}), 2.08(\mathrm{~m}, 1 \mathrm{H}), 2.10-2.60(\mathrm{~m}$, $4 \mathrm{H}), 2.62-2.90(\mathrm{~m}, 4 \mathrm{H}), 3.60(\mathrm{~m}, 1 \mathrm{H}), 3.72-3.76(\mathrm{~m}$, $2 \mathrm{H}), 3.98(\mathrm{t}, 1 \mathrm{H}, \mathrm{J}=15.94 \mathrm{~Hz}), 4.08(\mathrm{t}, 2 \mathrm{H}, \mathrm{J}=15.94$ $\mathrm{Hz}), 4.30(\mathrm{t}, 1 \mathrm{H}, \mathrm{J}=15.94 \mathrm{~Hz}), 4.60(\mathrm{~m}, 2 \mathrm{H}), 4.80$ (m, $1 \mathrm{H}), 5.01(\mathrm{~d}, 1 \mathrm{H}), 7.20-8.80(\mathrm{~m}, 7) \mathrm{ppm} .{ }^{13} \mathrm{C}$ NMR $\left(75.4 \mathrm{MHz}, \mathrm{CDCl}_{3}\right) \mathrm{d}_{\mathrm{c}}:$ 12.00, 18.86, 20.64, 23.80, $27.53,28.25,29.66,32.30,32.49,32.76,33.35$, $35.80,35.92,37.44,40.80,42.63,50.02,51.76$, $53.07,56.00,57.28,59.02,62.88,62.96,69.77$, $71.44,81.44,120.38,121.45,124.08,127.54$, $128.88,130.90,133.18,134.12,140.45,144.41$, 145.02, 146.20., 148.12, 155.33, 168.14,201.34, 202.22 ppm.El-MS m/z:804.26 (M+12). Anal. Calcd. for $\mathrm{C}_{44} \mathrm{H}_{51} \mathrm{Cl}_{3} \mathrm{~N}_{4} \mathrm{O}_{4}: \mathrm{C}, 65.55 ; \mathrm{H}, 6.38 ; \mathrm{Cl}, 13.19 ; \mathrm{N}$, 6.95; O, 7.94. Found: C, 65.52; $\mathrm{H}, 6.34$.

\section{RESULTS AND DISCUSSION}

There are many procedures for preparation of several androgen derivatives; nevertheless, despite its wide scope, have some drawbacks; for example, several agents used have limited stability and their preparation require special conditions ${ }^{8-10}$. Analyzing these data, we reporta straightforward route for synthesis of an androgen derivative using some strategies. The first stage was achieved by the synthesis of $N$-(1,10-phenanthrolin-5-ylmethyl) ethane-1,2-diamine (3). It is important to mention that there are reports which show the condensation of some compounds with formaldehyde and amino groups; for example, the synthesis of an androgen derivative (6-[(1-Ethynyl-1-hydroxy-10a,12a-dimethyl2,3,3a,3b,4,5,10,10a, 11,12,12a, dodecahydro-1H7-oxa-8-aza-dicyclopenta[a,h]phenanthren-6-ylmethyl)-amino]hexanoic acid) by the reaction of danazol and 6-aminohexanoic acid in presence of formaldheyde ${ }^{6}$. Therefore, in this study 3 was prepared by the reaction of 1,10-phenanthroline with ethylenediamine in presence of formaldehyde (Fig. 1). The ${ }^{1} \mathrm{H}$ NMR spectrum of 3 shows signals at $2.40 \mathrm{ppm}$ for amino groups; at 2.69 and $2.83 \mathrm{ppm}$ for arm bound phenanthroline fragment; at 3.53 $\mathrm{ppm}$ for methylene group bound to both amino and phenyl groups; at 7.27-8.87 ppm for phenanthroline fragment. The ${ }^{13} \mathrm{C}$ NMR spectrum of 3 contains at 41.50 and $53.48 \mathrm{ppm}$ for methylene groups involved in the arm bound to phenanthroline fragment; at $53.12 \mathrm{ppm}$ for amino group bound to phenyl group; at $120.90-152.03 \mathrm{ppm}$ for phenanthroline fragment. Finally, the presence of compound 3was further confirmed from mass spectrum which showed a molecular ion at $m / z 252.12$.

The second stage was achieved by reaction of the compound 3 with testosterone (Figure 2) resulting in imino bond formation involved in the compound 5(10,13-Dimethyl$3-\{2-[([1,10]$ phenanthrolin-5-ylmethyl)-amino]ethylimino\}-2,3,6,7,8,9,10,11,12,13,14,15,16, 17-tetradecahydro- $1 \mathrm{H}$-cyclopenta[a]phenanthren17-ol).It is noteworthy thatthere are several proceduresfor the synthesisofiminogroups are previously described intheliterature ${ }^{13-15}$; for example the synthesis of a steroid derivative by the reaction of $\mathrm{N}^{1}$-(2,3-dimethoxystrychnidin-10-yliden)-ethane-1,2diamine with a steroid derivative using boric acid as catalyst ${ }^{4}$. For this reason, in this study this reagent was used as catalyst in the reaction of the compound 3 with testosterone (Figure 1) to form the compound 5. The ${ }^{1} \mathrm{H}$ NMR spectrum of 5 shows signals at 0.80 and 1.02 ppm for methyl groups; at 0.92-1.00, 1.062.38, 3.68 and $5.90 \mathrm{ppm}$ for steroid nucleus; at 3.04 and $3.50 \mathrm{ppm}$ for methylene groups bound to both imino and amino groups; at $4.10 \mathrm{ppm}$ for methylene group bound to both phenyl and amino groups; at $4.70 \mathrm{ppm}$ for both amino and hydroxyl groups; at 7.00-7.80 for phenanthroline fragment. Finally, the presence of compound 5 was further confirmed from mass spectrum which showed a molecular ion at $\mathrm{m} / \mathrm{z}$ 522.30. 


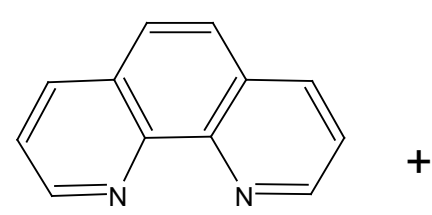

1

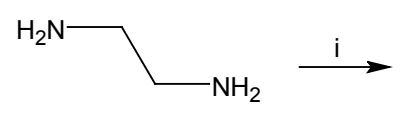

2

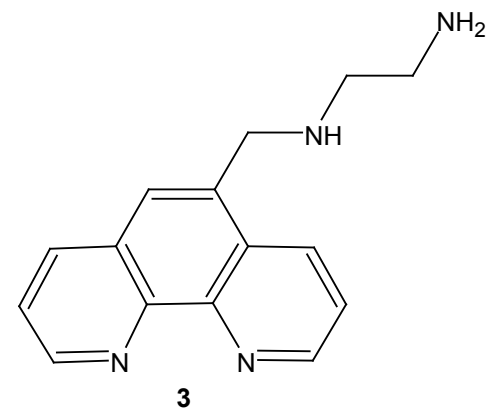

3

Fig. 1: Synthesis of $N$-(1,10-phenanthrolin-5-ylmethyl)ethane-1,2-diamine (3).

Reaction of 1,10-phenanthroline (1)with ethylenediamine (2) to form $3 . \mathrm{i}=$ formaldehyde/rt

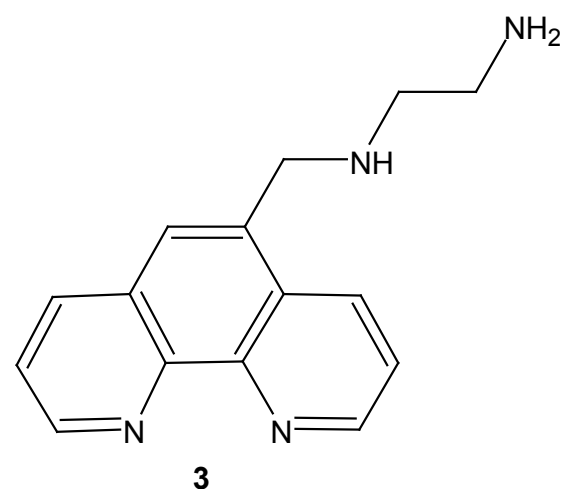

(c)<smiles>C[C@@]12CC/C(=N\CCNCc3cc4cccnc4c4ncccc34)C=C1CCC1C2CC[C@@]2(C)C1CC[C@@H]2O</smiles>

5

Fig. 2: Synthesis of 10,13-dimethyl-3-\{2-[([1,10]phenanthrolin-5-ylmethyl)-amino]-ethylimino\}-2,3,6,7,8, $9,10,11,12,13,14,15,16,17$-tetradecahydro-1H-cyclopenta[a]phenan- thren-17-ol (5). Reaction of $\mathrm{N}-(1,10-$ phenanthrolin-5-yImethyl)ethane-1,2-diamine (3)with testosterone (4) to form 5. ii = boric acid/rt 

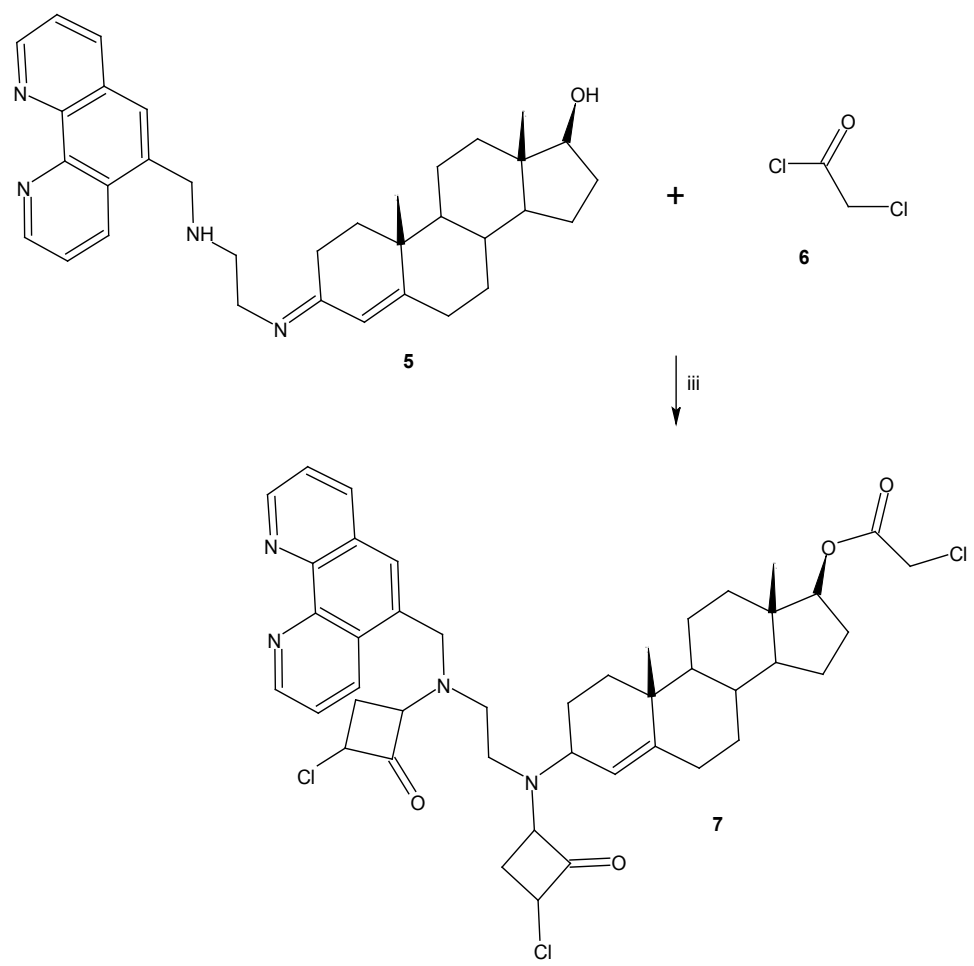

Fig. 3: Synthesis of Chloro-acetic acid 3-((3-chloro-2-oxo-cyclobutyl)-\{2-[(3-chloro-2-oxocyclobutyl)-[1,10]phenanthrolin-5-ylmethyl-amino]ethyl\}-amino)-10,13-dimethyl-2,3,6,7,8,9,10,11,1 2,13,14,15,16,17-tetradecahydro-1H-cyclopenta[a]phenanthren-17-yl ester (7). Reaction of 10,13-dimethyl-3-\{2-[([1,10]phenanthrolin-5-ylmethyl)-amino]-ethylimino\}-2,3, $6,7,8,9,10,11,12,13,14,15,16,17$-tetradecahydro-1H-cyclopenta[a]phenan- thren-17-ol

(5) with chloroacetyl chloride(6) to form 7. iii = triethylamine/rt

The third stepwas achieved bythe synthesisof7(Chloro-acetic acid 3-((3-chloro-2-oxocyclobutyl)-\{2-[(3-chloro-2-oxo-cyclobutyl)-[1,10] phenanthrolin-5-ylmethyl-amino]ethyl\}-amino)10,13-dimethyl-2,3,6,7,8,9,10,11,12, 13,14,15,16,17tetradecahydro-1H-cyclopenta[a]phenanthren-17-yl ester)byreactionof 5 with chloroacetylchloride in the presenceoftriet-hylamine.This method has been previously reported for other type of compound withbothaminoand iminogroupsinvolved in its structure chemical, which react with chloroacetylchloride to form cyclobutanone groups ${ }^{16}$. However, it isnoteworthy that hydroxylgroupof compound 5 was esterified with acetylchloride. This phenomenon is similar to esterification of other type of compounds ${ }^{17,18}$. The ${ }^{1} \mathrm{H}$ NMR spectrum of 7 shows signals at 12.00 and 18.86 ppm for methyl groups; at 20.64-29.66. 32.76-37.44, $42.63,51.76,56.00,59.02,81.44,121.45$ and 146.20 ppm for steroid nucleus; at 32.30, 32.49, 62.88-71.44 ppm for cyclobutanone groups; at 40.80 ppm for methylene group bound to both ester and chloride groups; at 50.02 and 53.07 ppm for methylene groups bound to both amino groups; at $57.28 \mathrm{ppm}$ for methylene group bound to both amino and phenyl groups; at 120.38, 124.45-145.02 and 148.12-155.33 ppm for phenanthroline group; at $168.14 \mathrm{ppm}$ for ester group; at 201.34 and 202.22 ppm for ketone groups. Finally, the presence of compound 7 was further confirmed from mass spectrum which showed a molecular ion at $m / z$ 804.26.

\section{CONCLUSIONS}

In this study, we reported an efficient andsimple method for synthesis of anandrogen derivative. It is important to mentionthat this method is highly versatile and the yield isgood. 


\section{REFERENCES}

1. Top S., Thibaudeau C., Vessieres A., Brule E., Le-Bideau F. and Joerger J. Organometallics. 28:1414-1424 (2009).

2. Moreira V., Vasaitis T., Guo Z., Njar V. and Salvador J. Steroids.73:1217-1227 (2008).

3. Mappus E., Chambon C., Fenet B., Ravel M., Grenot C. andCuilleron C. Steroids. 65:459481 (2000).

4. Figueroa-Valverde L., Díaz-Cedillo F., GarcíaCervera E., Pool Gómez E., López-Ramos M., Rosas-Nexticapa M. andMartinez-Camacho R. Arch. Pharm. Res. 36:1270-1278 (2013).

5. Figueroa-Valverde L., Díaz-Cedillo F., GarcíaCervera E., Pool Gómez E., Rosas-Nexticapa M. andLópez-Ramos M.Asian J.Chem.25: 6724-6726 (2013).

6. Figueroa-Valverde L., Díaz-Cedillo F., GarcíaCervera E., Pool Gómez E. andLópez-Ramos. E-J Chem. 7:S191-S196 (2010).

7. Yang-zhi L., Ji-song L., Yang L., Katsuya K., Klus G. and Brodie A. J. Med. Chem.40: $3297-$ 3304 (1997).

8. V. Santha Kumari, Orient. J. Chem., 28(1): 433-440 (2013).
9. L.F. Valverde, F. Diaz-cedillo. E.F. Cervera and E. Pool Gomez, Orient J. Chem., 28(3): 1085-1090 (2012).

10. Herr M. and Heyl F. J. Am. Chem. Soc.75:59275930 (1953).

11. Stevenson D., Neville J.and Akhtar M. J. Chem. Soc. Chem. Commun.1078-1080 (1985).

12. Potter G., Banie E., Jarman M. and Rowlands M. J. Med. Chem. 38:2463-2471 (1995).

13. Shirayev A., Moiseev I. and Karpeev S.Arkivok.4:199-207 (2005).

14. Uppiah U., Bhowon M. and Jhaumeer S.E-J Chem.6:S195-S200 (2009).

15. Hania M.E-J Chem.6:629-632 (2009).

16. Figueroa-Valverde L., Díaz-Cedillo F., RosasNexticapa M., García-Cervera E., Pool Gómez E. and López-Ramos M.Oriental J. Chem. 29:921-925 (2013).

17. Martin A., Sanchez-Chaves M., Arranz F. Reac.Func.Polym.39:179-187(1999).

18. Bai F., Li R., Yang X. and Li S.Polymer Int. 55:319-325 (2006). 